\title{
Physical Activity, Physical Fitness \& Health: Distilling Guidelines for Young People 體育活動、體能與健康：青少年的標準指引
}

\author{
Michael Chia Quek Jin Jong \\ Physical Education \& Sports Science Group, National Institute of Education, \\ Nanyang Technological University, SINGAPORE
}

謝永和 郭仁勇

新加坡南洋理工大學敉育學院體育與運動科學組

\begin{abstract}
The associations between physical activity and health; physical activity and physical fitness; and physical fitness and health in young people are complex and difficult to tease out. The complexities in the relationships are in part due to the difficulties faced in appropriately appraising physical activity in young people. Physical fitness standards tend to be based on norms that have been established within a population. These norms do not provide useful information about what are acceptable fitness standards for young people of different ages. Physically fit young people may not necessarily also be physically active young people and there are concerns that the pattern of increased physical inactivity among young people may have a negative impact on their health status in later years. Current recommendations for young people mirror the thinking that discontinuous physical activity of a moderate intensity that is repeated many times over on a daily basis.
\end{abstract}

\section{摘 要}

青少年中體育活動與健康, 體育活動與體能以及體能與健康之間有著複雜的關係併難以理順。之所以複雜, 其部分原因是 因為不能正確地評估青少年的體育活動。體能的標準往往基於大眾中建立的一些準則，而這些準則併不適用于不同年齡階段的 青少年。體格較好的青少年併不一定都是那些經常參加體育活動的人。但在青少年中不參加體育活動的人數增加的現象卻令人 擔憂, 這將在今後的幾年中對他們的健康產生不良的影響。目前對青少年所推薦的體育活動形式是間斷性的中等強度的運動， 即在一天中反覆多次的短時間運動。

\section{Introduction}

Information about young people, physical activity, physical fitness and their well-being is peppered with contrasts and contradictions. The paradox is understandable. On the one hand, national and regional swimming held by teenagers are commonplace, many top female gymnasts are almost always at the school-going age and locally, 13-year-old girl has come in first in a national half marathon, beating many experienced adult athletes. On the other hand, the perceptions that young people's physical fitness has deteriorated over the years, exacerbated by a curtailment of young people's freedom to cycle, walk and play outdoors, cannot be discounted. Many health protagonists argue that young people spend far too much time watching television or using the computer either for work, or for play. Teachers of physical education are concerned as apparently less young people do well in fitness tests whilst army recruits are believed to be less fit than in previous years. Such contrasts and contradictions evoke the question as to whether current levels of physical fitness and physical activity of young people are adequate and appropriate to ensure optimal growth and health into the adult years. 
The question is difficult to answer simply because the associations between physical fitness and health; physical activity and health; physical activity and physical fitness are complex, and cause and effect relationships are impossible to tease out. Moreover, the methodologies that have been used to assess both physical fitness and physical activity have been far from universal, thus further clouding the issue. For instance, there are many physical fitness test batteries and depending on how the results are used, most suffer from a lack of validity, and the data garnered from the tests cannot provide very useful information. Physical activity has many dimensions to it such as type of activity, duration and intensity of the activity, frequency of the activity and caloric expenditure. The methods used to assess the levels of physical activity such as heart rate monitoring or recall questionnaires do not capture all the dimensions that typify physical activity. These complexities make it difficult to distill, from the available research, definitive guidelines and recommendations for optimal activity and levels of fitness that will contribute to good health in young people, across all cultures.

\section{Discerning between Physical Activity and Physical Fitness}

Physical activity is a behaviour that is often very variable and it is a complex behaviour with many dimensions - e.g. duration, intensity, type and frequency. Physical activity results in energy expenditure that can be expressed in absolute or relative terms. Additionally physical activity can be considered as voluntary (e.g. leisure time activity) or unavoidable (e.g. as part of work). Many difficulties abound when it comes to appraising physical activity since no single method can adequately capture all the aspects of physical activity. A questionnaire that focuses on sport and fitness training alone is likely to miss much activity that is performed in the course of work or travel. For example, a person who plays no sport but walks daily to school can potentially be erroneously classified as a sedentary person. Such misclassifications can weaken the relationships between physical activity and health variables. A suggestion to better appraise physical activity is to use a combination of methods to reduce the likelihood for misclassification.

Physical fitness is a measure of a person's capacity to do work. Whilst physical activity is a behaviour, physical fitness is an attribute. Fitness may be further categorized as fitness contributing to health and fitness contributing to skill. The health dimensions of fitness comprise the components-muscular strength, muscular endurance, cardiovascular capacity, joint flexibility and body composition. The skill-related fitness has components- agility, balance, speed and power. An important question to ask about fitness is what sort of fitness is required for young people of different ages? The physical fitness required of an active young person is different from that required of a young athlete who is competing at a high level of competition. The compositions of the fitness tests conducted in schools (i.e. NAPFA) and in the army (i.e. IPPT) in Singapore are a marriage of health and skill-related fitness components. Results from fitness tests are more secure when compared to results from physical activity assessments but how the fitness results are interpreted and used merit further discussion. Tests devised to assess physical fitness must therefore be appropriate and levels of fitness required for the active young person and levels of fitness required of the young athlete must be identified. The American College of Sports Medicine recommends that physical fitness test scores be interpreted in relation to acceptable standards rather than by normative comparison (ACSM, 1995). Research into establishing acceptable standards for all fitness components in young people of different age groups is urgently needed, but preliminary standards should be developed based on the current available evidence, and professional opinion.

It is a common assumption that physically fit people are also physically active on a regular basis. This assumption does not always hold water. Many studies have shown that the relationship between physical fitness and physical activity is low (Armstrong \& Welsman, 1997). Indeed, heredity and maturation impacts performance in fitness tests significantly (Bouchard, 1990) and these factors may have a stronger influence on test results than the level of activity engaged by young people. Moreover, research data have suggested that the "trainability of aspects of physical fitness' is also genetically determined (Bouchard, Dionne, Simoneau \& Boulay, 1992). It appears therefore that physical active young people can have genes that limit their level of physical fitness while sedentary young people could have genes that predispose them to higher levels of fitness.

\section{Physical Activity and Physical Fitness Associations with Disease and Health in Adults}

In adults, the relationships between physical activity and health and physical fitness and health are clearer and more secure. Indeed, the evidence that both fitness and activity promotes health comes almost exclusively on adult data. In adults, levels of physical activity and physical fitness are inversely related to mortality (Blair, Kohl, Paffenbarger, Clark, Cooper \& Gibbons, 1989; Paffenbarger, Hyde, Wing \& Hsieh, 1986). Higher levels of physical activity and fitness in adults have been shown to reduce the risk of coronary heart disease (CHD), stroke, hypertension, type II diabetes, osteoporotic fractures, depression and certain cancers. A meta-analysis of more than 40 studies indicates that physically 
inactive adults are 1.9 times more likely to develop CHD than in physically active adults, independent of other risk factors (Berlin \& Colditz, 1990). With regards to the level of physical fitness, Blair et al (1996) reported that low levels of fitness increased the risk of all-cause mortality by 1.52 times in men and 2.10 times in women.

At present it is uncertain whether physical activity or physical fitness is more important to health. What is clear however is that current levels of physical activity are more important than levels that were attained in the past, for harvesting health benefits. There is also the realization that the recommendations for exercise needed to attain health-related benefits might differ from what are necessary for fitness benefits. The quality and quantity of exercise that is needed to confer health-related benefits however might not have much impact on cardiovascular fitness. Although, physical inactivity carries an equal primary risk of CHD as the other major risk factors (i.e. smoking, hypertension and high cholesterol levels), it is nearly four times more prevalent in the adult population (National Health Survey, 1998). Sedentary living is therefore the most health-detrimental behaviour in terms of the extent of the adult population that is exposed to the risk. An optimistic viewpoint is that reversing sedentary living habits represents the biggest scope for health gain for the population. $17 \%$ of Singaporeans aged between 18 and 60 years exercise for least 30 minutes at a stretch, thrice a week (National Health Survey 1998). Reversing the propensity for sedentary living is not easy. To encourage people to return to physically more active lifestyles, health-related activity guidelines have been formulated for adults. The central message of the recommendation is to accumulate 30 minutes of moderate intensity activity (equivalent to brisk walking for most people) for at least 5 days of the week (Department of Health and Social Services, 1996). A starting point for someone who was previously totally physically inactive is the accumulation of 30 minutes of activity on one day of the week. For the more motivated and fitness inclined, the volume of exercise can be increased gradually up to exercising the major muscle groups continuously for 30-60 minutes at a stretch, three times a week.

The new recommendations strike a balance between what is desirable and what is achievable by most people. While it is known that most health benefits can accrue with the moderate message, it is recognized that a more vigorous exercise regimen may be necessary if changes in blood pressure in hypertensives are to be realized (Blair, Kohl, Gordon \& Paffenbarger, 1992). However and importantly, such high levels of exercise are not necessary for most health benefits to accrue. Therefore, the widely held view that doing some aerobic-type exercise (running, swimming, or skipping) three times a week is in some way a health-related benefit threshold should now be rightfully discarded.

\section{Physical Activity and Physical Fitmess Associations with Disease and Health in Young People}

Young people love to play and have a natural inclination for movement. Given the freedom, young children will play or invent active ways of passing time such as tag-games, skipping, cycling, skating and climbing. Such activities invariably provide a large volume of physical activity, involve large muscle groups and provide a means of developing muscular strength, muscular endurance, agility, flexibility, speed and cardiovascular endurance. As young people become older such as during the teenage years, and especially in girls, they become less physically active as more sedentary pursuits are chosen. This is apparently normal and data support that this is also true in other animal species. However, the situation becomes a concern in modern society when physical activity levels decline too fast and too soon during the childhood years because of the indulgences in television watching and computer engagement. In adults, very low levels of physical activity are health compromising. If young people become entrenched with sedentary living, then the situation becomes a "problem in the making".

Appropriate levels of body weight and adiposity are related to good health and excess body fat is associated with a myriad of ailments in adulthood. Unfortunately it appears at least in the developed world, levels of over-fatness in the young are increasing. Current classifications for being overweight and over-fat when young include being $120 \%$ of ideal body mass, the Body Mass Index (BMI), body mass-for-age percentiles and skinfold thickness. The $95^{\text {th }}$ percentile for weight-for-age is used as a cut-off for obesity while the $85^{\text {th }}$ percentile is commonly used to classify young people who are at risk of being overweight. Bar-Or and Baranowski (1994) recommend that when using classifications that are based on body mass, the term over weight is preferred to the term obesity, which refers to an excess of body fat. Dwyer and Blizzard (1996) suggested using individual biomedical status and sum of skinfolds to define obesity. In their study, 'cut-offs' of 30\% of body mass as fat in girls and $20 \%$ of body mass as fat in boys are suggestive of obesity. The BMI is widely used to classify people as over-weight or obese in many studies in adults and young people. Though convenient, the main criticism of using BMI is the failure of the index to differentiate between mass and fat and also the apparent instability of the measure in growing young people. Tell, Tuomilehto, Epstein and Strasser (1986), recommended arbitrary age-related BMIs for obesity in young people. They proposed that for 14 years or less, a BMI of $19-20 ; 15$ years of age, a BMI of 25 , and 16 years or older, a BMI of 28 . However, a main problem of using calendar age for any form of classification is that it may not necessarily reflect developmental age. 
It is assumed that being over-fat and overweight in childhood predispose the young person to increased risks of heart disease, high blood pressure and stroke, non-insulin dependent diabetes and certain forms of cancers in adulthood. The data to date however has been more suggestive than definitive. Most associations between juvenile obesity and disease states in adulthood are weak but the concern is defensible. This is because being regular exercisers or being physically active on most days of the week help to maintain appropriate levels of adiposity. There are ample examples of increased levels of obesity in groups where spontaneous physical activities have declined or been curbed. Contrarily, levels of obesity in most athletic populations are rare. Additionally, juvenile obesity tends to lead to adult obesity and adults who were obese children tend to have increased higher risk of premature death from lifestyle diseases, irrespective of adult body mass (Must, 1996). Confounding levels of body fatness can largely explain the relationship between physical fitness, in particular cardiovascular fitness, and health outcomes in young people. In order words, low levels of body fatness are associated with higher levels of physical fitness and reduced risk of cardiovascular disease. This relationship is also observed in adults.

Despite the absence of robust data to support the assertion that physical activity and physical fitness are beneficial to health in young people, there are intuitive biological and behavioural arguments in favour of promoting a physically active lifestyle to all young people, and prudence dictates that some sort of guidelines be formulated as least to show the way forward. Guidelines enunciated for adults tend to support a health-related threshold requirement where the exercise had to be sustained for the development of cardiovascular fitness. The sort of required behaviour is not only beyond the attainment of most children; it is also uncharacteristic of young people's natural physical activity pattern. Moreover it may also be unrelated to the amount of activity that is necessary to derive a health-enhancing effect. Young people have little proclivity to maintain vigorous bouts of intense exercise, therefore, adult fitness guidelines that advocate continuous exercise do not appeal to them. Activity guidelines for young people must take into account issues of activity adoption and longterm maintenance.

Recent studies show that accumulating three bouts of 10minute exercise is considered as having the same effect as one bout of 30 minutes of exercise. One recent recommendation is to have young people be engaged in moderate intensity activity on a daily basis for an accumulated time of 60 minutes or more per day in activities that promote strength, flexibility and bone health (Biddle, Cavill \& Sallis, 1998). Echoing similar recommendations, Pangrazi (2000), advises that primary school children accumulate between 30 to 60 minutes of age-appropriate physical activity on all or most days of the week. Given that young people's play is typified by intermittent bouts of activity of varying intensity and duration, several activity sessions distributed throughout the day are necessary to accumulate adequate activity time to meet the recommendations. These enlightened recommendations are more holistic and realistic in their development of health, warrant serious consideration and are worthy of pursuit.

\section{References}

American College of Sports Medicine. Pronouncements. Position Statements and Opinion Statements. (1995). pp.1-2.

Armstrong, N., \& Welsman, J. (1997). Young people and physical activity. Oxford, London: Oxford University Press.

Bar-Or, O., \& Baranowski, T. (1994). Physical activity, adiposity and obesity among adolescents. Pediatric Exercise Science, $6,348-360$.

Berlin, J.A., \& Colditz, A. (1990). A meta-analysis of physical activity in the prevention of coronary heart disease. American Journal of Epidemiology, 132, 612-627.

Biddle, S, Cavill, N., \& Sallis, J. (1998). Policy framework for young people and health enhancing physical activity. In Young and active? Health Education Authority. pp. 316. London.

Blair, S.N., Kohl, H.W., Gordon, N.F., \& Paffenbarger, R.S. J. (1992). How much physical activity is good for health? Annual Review of Public Health, 13, 99-126.

Blair, S.N., Kohl, H.W., Paffenbarger, R.S.J., Clark, D.G., Cooper, K.H., \& Gibbons, L.W. (1989). Physical fitness and all-cause mortality: a prospective study of healthy men and women. Journal of American Medical Association, $262,2395-2401$.

Bouchard, C. (1990). Heredity, fitness and health. Champaign, IL: Human Kinetics.

Bouchard, C., Dionne, F., Simoneau, J., \& Boulay, M. (1992). Are American children and youth fit? Research Quarterly for Exercise and Sport, 63, 96-106.

Department of Health and Social Services. Strategy statement on physical activity. (1996). Department of Health, London. 
Dwyer, T., \& Blizzard, C. (1996). Defining obesity in children by biological endpoint rather population distribution. International Journal of Obesity, 20, 472-480.

Must, A. (1996). Morbidity and mortality associated with elevated body weight in children and adolescents. American Journal of Clinical Nutrition, 63, 445S-447S.

National Health Survey. (1998). Ministry of Health. Singapore.

Paffenbarger, R.S., Hyde, R.T., Wing, A.L., \& Hsieh, C. Physical activity, all-cause mortality and longevity of college alumni. New England Journal of Medicine, 314, 605-613.

Panagrazi, R. (2000). Promoting physical activity for youth. ACHPER, 2, 18-21.

Tell, G.S., Tuomilehto, J., Epstein, F.H., \& Strasser, T. (1986). Studies of arteriosclerosis determinants and precursors during childhood and adolescence. Bulletin of the World Health Organisation, 64, 595-605. 